\title{
Optical Properties of Multi-Component Metallic Nanoclusters Formed in Silica by Sequential Ion Implantation
}

\author{
Raymond A. ZUHR and Robert H. MAGRUDER, III* \\ Solid State Division, Oak Ridge National Laboratory, Oak Ridge, TN. 37831, USA \\ *Department of Applied Engineering and Sciences Vanderbilt University, Nashville TN. 37235, USA
}

(Received February 14, 1997)

\begin{abstract}
While there are stringent performance criteria, as well as competition from resonant and non-resonant semiconductor quantum dot materials, organic materials, and other glass systems, nanometer dimension metal particle glass composites have some properties that may make them viable candidates for all optical switching networks: large third order nonlinear response, picosecond switching and relaxation times, thermal and chemical stability, high laser damage threshold, and low two photon absorption. Metal nanocluster composites can be fabricated by ion implantation. It has been shown that particle size can be controlled by the total dose, current density, and substrate temperature. The depth of the implanted particles can be controlled by the implantation energy. The formation and size of these colloids when formed by ion implantation are highly dependent upon the composition of the substrate. Post implantation processing can subsequently be used to alter the size and size distribution of the colloids. Sequential ion implantation can be used to extend the ion implantation method of forming metal nanocluster glass composites by allowing the formation of multi-component particles in glass. This technique has been demonstrated to significantly alter the composition of the metal particles formed. As a consequence the formation of multi-component nanoclusters results in changes in both the linear and nonlinear optical properties of the composite that are not possible with single element colloids. Here we review the formation and optical properties of multi-component nanoclusters formed by sequential implantation in silica compared to their single element counterparts. In this paper we focus on work done by the authors on the following systems; $\mathrm{Ag} / \mathrm{Sb}, \mathrm{Ag} / \mathrm{Cu}$ and $\mathrm{Ag} / \mathrm{Cd}$.
\end{abstract}

\section{Introduction}

While there are stringent performance criteria, as well as competition from resonant and non-resonant semiconductor quantum dot materials, organic materials, and other glass systems, ${ }^{1)}$ nanometer dimension metal particle glass composites have some properties that may make them viable candidates for all optical switching networks: large third order nonlinear response, picosecond switching and relaxation times, thermal and chemical stability, high laser damage threshold, and low two photon absorption.")

Nanometer-size metallic particles have been used for millennia to color melt-glasses for decorative purposes and for passive optical elements such as filters. Particle sizes and size distributions as well as glass coloration can be controlled across a broad region of the visible spectrum by thermal annealing. ${ }^{2}$ Metal nanocluster composites can also be fabricated by ion implantation, a technique that permits control of depth, concentration and, to some extent, chemical state of the implanted ions.
Arnold and Borders ${ }^{3)}$ initially used this technique to form $\mathrm{Ag}$ and $\mathrm{Au}$ colloids in silicate glasses, while others have used the technique to form $\mathrm{Au}, \mathrm{Ag}, \mathrm{Sn}, \mathrm{Cu}, \mathrm{Sb}$, $\mathrm{Pb}, \mathrm{Bi}, \mathrm{Ti}, \mathrm{Fe}, \mathrm{Cr}, \mathrm{Mn}$, and $\mathrm{Ga}^{4 \sim 11)}$ colloids in different glass substrates. It has been shown that particle size can be controlled by the total dose, current density, and substrate temperature. ${ }^{12,13)}$ The depth of the implanted particles can be controlled by the implantation energy. The formation and size of these colloids when formed by ion implantation are highly dependent upon the composition of the substrate. ${ }^{14,15)}$ Post implantation processing can subsequently be used to alter the size and size distribution of the colloids. ${ }^{16)}$

Sequential ion implantation can be used to extend the ion implantation method of forming metal nanocluster glass composites by allowing the formation of multicomponent nanometer dimension metal particles in glass. ${ }^{17,18)}$ This technique has been demonstrated to significantly alter the composition of the metal particles formed. Composition changes engender changes in the electronic structure of the colloids present. As a consequence the for- 
mation of multi-component nanoclusters results in changes in both the linear and nonlinear optical properties of the composite that are not possible with single element colloids. ${ }^{19,20)}$

Here we review the formation and optical properties of multi-component nanoclusters formed by sequential implantation in silica compared to their single element counterparts. In this paper we focus on work done by the authors on the following systems; $\mathrm{Ag} / \mathrm{Sb}, \mathrm{Ag} / \mathrm{Cu}$ and $\mathrm{Ag} / \mathrm{Cd}$.

\section{Theory}

The optical properties of these metal colloid-glass composites can be described using effective medium theory for small non interacting particles in a dielectric.") The linear response for colloids with diameters less than $\lambda / 20$, where $\lambda$ is the wavelength of the incident radiation, is reasonably described by effective medium theory in the electric dipole approximation ${ }^{1,2)}$ and is given by

$$
\alpha=\frac{18 \pi n_{\mathrm{d}}{ }^{3}}{\lambda} \cdot \frac{\mathrm{p} \varepsilon_{2}}{\left[\varepsilon_{1}+2 n_{\mathrm{d}}{ }^{2}\right]^{2}+\varepsilon_{2}{ }^{2}}
$$

where $\alpha$ is the absorption coefficient, $\varepsilon(\lambda)=\varepsilon_{1}+i \varepsilon_{2}$ is the dielectric constant of the metal, $p$ is the volume fraction of the metal particles, and $n_{\mathrm{d}}$ is the index of refraction of the dielectric host. The absorption is expected to exhibit a peak at the surface plasmon resonance frequency for which the condition $\varepsilon_{1}+2 n_{\mathrm{d}}^{2}=0$ is met. The surface plasmon resonance frequency depends on the electronic properties of the metal colloids and on the index of refraction of the host dielectric, $n_{\mathrm{d}}$.

The third order nonlinear susceptibility, $\chi_{\text {eff }}^{(3)}$ can be expressed as ${ }^{1)}$

$$
\chi_{\mathrm{eff}}^{(3)}=p f_{\mathrm{c}}(\omega)\left|f_{\mathrm{c}}(\omega)\right|^{2} \chi_{\mathrm{m}}^{(3)} \text { with } f_{\mathrm{c}}(\omega)=\frac{3 n_{\mathrm{d}}{ }^{2}}{\varepsilon_{1}+2 n_{\mathrm{d}}{ }^{2}}(2)
$$

and where $f_{c}(\omega)$ is the local field factor and $\chi_{\mathrm{m}}^{(3)}$ is the nonlinear susceptibility of the metal colloids. The index of refraction and the intensity dependent term are related to the above quantities by Ref.22)

$$
n=n_{\mathrm{o}}+n_{2} \mathrm{I} \text { and } n_{2}=\frac{12 \pi}{n_{\mathrm{o}}} \operatorname{Re}\left[\mathcal{X}_{\mathrm{eff}}^{(3)}\right]
$$

where $n_{\mathrm{o}}$ is the linear index of refraction and $n_{2}$ is the intensity dependent component. From equation (2) a potentially large enhancement of the effective nonlinear susceptibility and in turn $n_{2}$ near or at surface plasmon resonance frequency is possible due to local field effects.

\section{Experimemt}

All samples were made by implanting the metal ions into Corning 7940 high purity silica substrates. The implantation energies were chosen from calculations using TRIM 89 to target energies that would overlay the depths of implantation for each metal. The conditions for
Table 1 Ion species and implantation parameters.

\begin{tabular}{lccl}
\hline Ion Species & $\begin{array}{l}\text { Energy } \\
(\mathrm{keV})\end{array}$ & $\begin{array}{l}\text { Current Density } \\
\left(\mu \mathrm{A} / \mathrm{cm}^{2}\right)\end{array}$ & $\begin{array}{l}\text { Doses } \\
\left(10^{16} \text { ions } / \mathrm{cm}^{2}\right)\end{array}$ \\
\hline $\mathrm{Ag}$ & 305 & 1.3 & 3,6 and 9 \\
$\mathrm{Sb}$ & 320 & 5.0 & 3 \\
$\mathrm{Cu}$ & 160 & 3 & 3,6 and 9 \\
$\mathrm{Cd}$ & 300 & 1.5 & 6 \\
\hline
\end{tabular}

implantation are given in Table $\mathbb{1}$. For all sequentially implanted systems the nominal total doses as determined by current integration were $12 \times 10^{16}$ ions $/ \mathrm{cm}^{2}$. Single element implantations were made for each ion species using the same experimental conditions as for the sequentially implanted samples.

Rutherford backscattering measurements with $2.3 \mathrm{MeV}$ $\mathrm{He}^{++}$ions were used to measure the depth profiles of the implanted metal ion species.

The size distributions and geometrical structure of the nanoclusters in these composite materials were determined by transmission electron microscopy (TEM). Sample preparation has been previously described. ${ }^{17}$ The samples were examined in a $200-\mathrm{kV}$ scanning transmission electron microscope. Bright field (BF) and dark field (DF) imaging, and selected-area electron diffraction (SAD) techniques were used to characterize the implanted layer of the silica disks.

Linear optical absorption measurements were made at room temperature in air from 900 to $200 \mathrm{~nm}$ using a dual beam spectrometer (Cary 5). All samples were measured using an unimplanted sample in the reference beam. The absorption spectra were measured at three different positions on each sample and are reported as optical density (OD). The scatter in these measurements at these different positions was less than $1 \%$. The nonlinear index of refraction, $n_{2}$, for the $\mathrm{Ag} / \mathrm{Cu}$ system was measured at $570 \mathrm{~nm}$ using the Z-scan method described previously. ${ }^{13)}$ The laser used for these experiments was a cavity dumped tunable dye laser with a $\sim 6$ ps pulse duration. The laser was operated at $3.8 \mathrm{MHz}$. The average power was $250 \mathrm{~mW}$ in the $\mathrm{TEM}_{\mathrm{oo}}$ mode and the peak irradiance for a focal spot of $25 \mathrm{~mm}$ in radius was $\sim 5 \times$ $10^{8} \mathrm{~W} / \mathrm{cm}^{2}$. The error in these measurements in all cases was less than $20 \%$.

\section{Results and Discussiom}

\section{4. $1 \mathrm{Ag} /$ Sb System}

$\mathrm{The} \mathrm{Ag}$ and $\mathrm{Sb}$ were implanted with a ratio of $9 \mathrm{Ag}$ to $3 \mathrm{Sb}$. This ratio was chosen because $\mathrm{Ag}_{3} \mathrm{Sb}$ is a stable compound of the $\mathrm{Ag}-\mathrm{Sb}$ system. Single element implanted samples were made using doses of $3 \times 10^{16} \mathrm{Sb}$ and $9 \times 10^{16} \mathrm{Ag}$. The sequentially implanted samples were made using these same doses of $\mathrm{Sb}$ and $\mathrm{Ag}$. One sample 


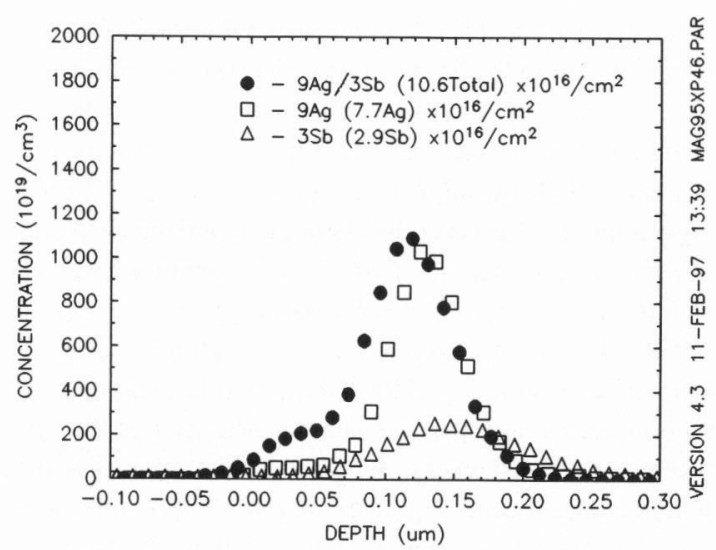

Fig. 1 Ion distributions as a function of depth from the surface for the sample sequentially implanted with nominal doses of $9 \times 10^{16} \mathrm{Ag}$ ions $/ \mathrm{cm}^{2}$ and $3 \times 10^{16} \mathrm{Sb}$ ions $/ \mathrm{cm}^{2}$. Numbers in parentheses are retained doses as measured by RBS.

( $9 \mathrm{Ag} / 3 \mathrm{Sb}$ ) was made by implanting the $\mathrm{Ag}$ first then the $\mathrm{Sb}$, and a second sample ( $3 \mathrm{Sb} / 9 \mathrm{Ag}$ ) by implanting the $\mathrm{Sb}$ first then the Ag.

Figure 1 shows the RBS spectra for the sequentially implanted sample $9 \mathrm{Ag} / 3 \mathrm{Sb}$ and the single element implants of $3 \mathrm{Sb}$ and $9 \mathrm{Ag}$. The RBS spectrum for the sequentially implanted sample is a Gaussian with the peak at $\sim 0.12$ microns and a FWHM of $\sim 0.1$ microns.

Micrographs of the $9 \times 10^{16} \mathrm{Ag}$ sample and the $3 \times 10^{16}$ $\mathrm{Sb}$ sample reveal that for the $\mathrm{Ag}$ sample the particles are spherical in shape with a bidispersed particle size distribution. Mean particle size is $24.2 \mathrm{~nm} \pm 1.8 \mathrm{~nm}$ with a standard deviation of $12.6 \mathrm{~nm}$. Analysis of selected area electron diffraction rings indicates that the particles present are FCC silver. For the Sb implanted sample the nanoclusters are approximately spherical with a much smaller particle size and a much narrower distribution than in the Ag samples. Mean particle size was $6.0 \mathrm{~nm} \pm 1.8$ $\mathrm{nm}$ with a standard deviation of $1.0 \mathrm{~nm}$. Electron diffraction ring patterns of the $\mathrm{Sb}$ implanted sample are diffuse rings characteristic of non crystalline $\mathrm{Sb}$ colloids.

Figure 2 shows bright field images of the implanted layer for the $9 \mathrm{Ag} / 3 \mathrm{Sb}$ and $3 \mathrm{Sb} / 9 \mathrm{Ag}$ samples. The microstructure of the $3 \mathrm{Sb} / 9 \mathrm{Ag}$ implanted sample displays a distributed particle size of spherical colloids, while that of the $9 \mathrm{Ag} / 3 \mathrm{Sb}$ implanted sample is markedly different. The unusual microstructure of the $9 \mathrm{Ag} / 3 \mathrm{Sb}$ implanted sample is characterized by a large spherical colloid surrounded by annular clusters of smaller spherical colloids. Mean particle size for the $9 \mathrm{Ag} / 3 \mathrm{Sb}$ is 11.03 $\mathrm{nm} \pm 1.8 \mathrm{~nm}$ with a standard deviation of $7.8 \mathrm{~nm}$ and for the $3 \mathrm{Sb} / 9 \mathrm{Ag}$ is $9.65 \mathrm{~nm} \pm 1.8 \mathrm{~nm}$ with a standard devi-

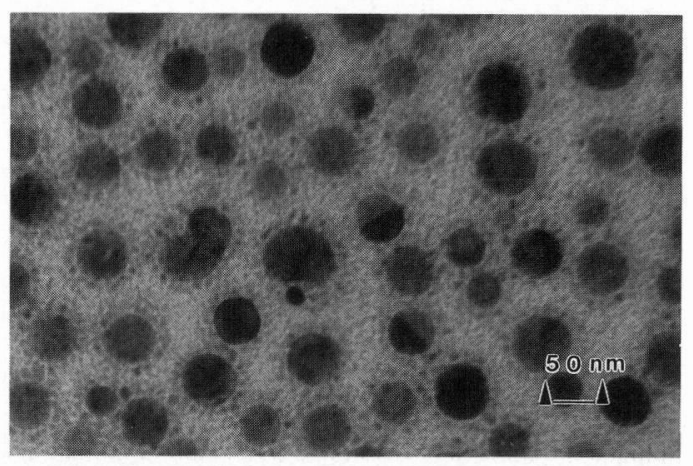

(a)

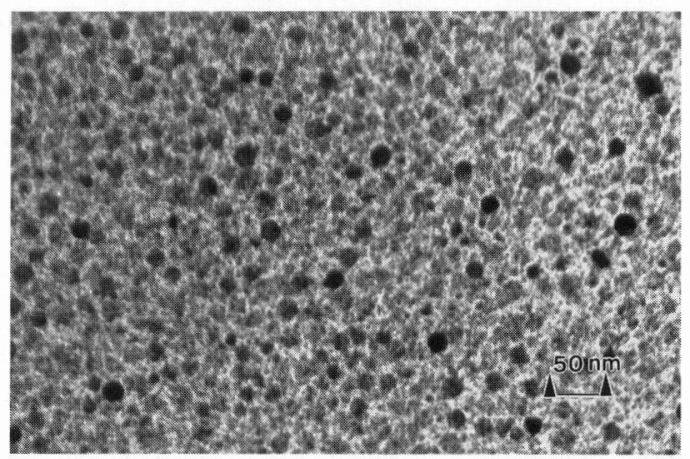

(b)

Fig. 2 Bright field images of the sequentially implanted $\mathrm{Ag}$ and Sb samples, (a) $9 \mathrm{Ag} / 3 \mathrm{Sb}$ and (b) $3 \mathrm{Sb} / 9 \mathrm{Ag}$.

ation of $4.0 \mathrm{~nm}$. While the microstructure is clearly different the average particle sizes are similar. In both sequentially implanted samples the mean particle size is significantly smaller and the distribution narrower than the $9 \mathrm{Ag}$ sample. Selected area diffraction patterns for the 9 $\mathrm{Ag} / 3 \mathrm{Sb}$ and the $3 \mathrm{Sb} / 9 \mathrm{Ag}$ samples reveal that colloids in these samples are crystalline. The d-spacings obtained from the ring pattern for the $9 \mathrm{Ag} / 3 \mathrm{Sb}$ and the $3 \mathrm{Sb} / 9 \mathrm{Ag}$ samples are consistent with elemental $\mathrm{Ag}$ and an $\mathrm{Ag}_{3} \mathrm{Sb}$ phase for both sequentially implanted samples.

The optical spectra for each of the four samples are shown in Fig. 3. The absorption spectrum for the $9 \times$ $10^{16} \mathrm{Ag}$ sample is dominated by an absorption peak at $\sim$ $400 \mathrm{~nm}$ and a second peak centered at $\sim 610 \mathrm{~nm}$. The spectrum for the $3 \times 10^{16} \mathrm{Sb}$ sample displays no resonance peaks, simply increasing absorption with decreasing wavelength with an approximate $1 / \lambda$ dependence. The absorption spectrum for the $3 \mathrm{Sb} / 9 \mathrm{Ag}$ sample displays two overlapping absorption peaks centered at $\sim 403$ $\mathrm{nm}$ and $\sim 485 \mathrm{~nm}$. The position of these peaks was determined by a simple curve fit of a background absorption due to a $1 / \lambda$ dependence expected for nanometer 


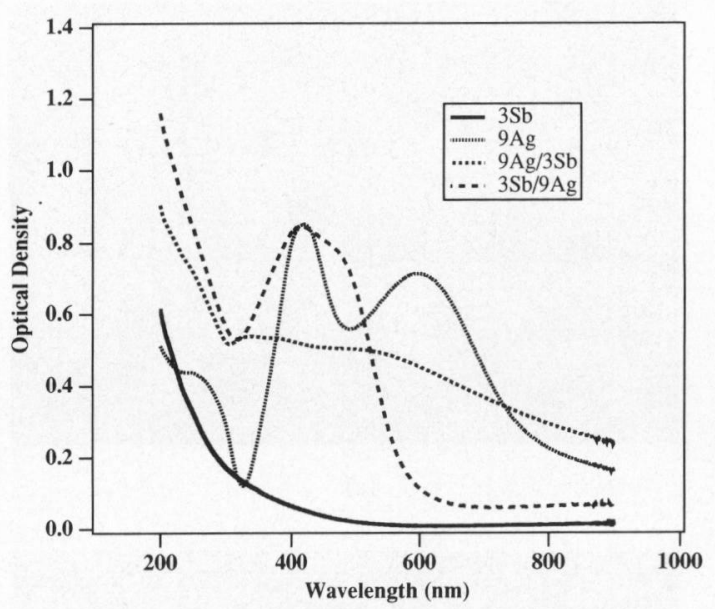

Fig. 3 Optical density as a function of wavelength for $3 \mathrm{Sb}, 9$ $\mathrm{Ag}, 9 \mathrm{Ag} / 3 \mathrm{Sb}$, and $3 \mathrm{Sb} / 9 \mathrm{Ag}$.

dimension colloids and two Gaussian peaks. The best fit was obtained for peaks centered at $403 \mathrm{~nm}$ and $485 \mathrm{~nm}^{23}$ ) The spectrum for the $9 \mathrm{Ag} / 3 \mathrm{Sb}$ sample exhibits no sharp absorption peaks. However, two broad absorption peaks centered at $\sim 335 \mathrm{~nm}$ and $\sim 534 \mathrm{~nm}$ are present.

Comparison of the $9 \times 10^{16} \mathrm{Ag}$ and $3 \times 10^{16} \mathrm{Sb}$ samples reveals that although the Ag sample contains dramatically larger particles than does the Sb sample, the implanted layer of the Sb sample displays a higher numerical density of particles. This is attributed to the more efficient nucleation of $\mathrm{Sb}$ colloids relative to growth rate than that of the $\mathrm{Ag}$ colloids. Once a critical radius of $\mathrm{Ag}$ has been reached it is easier for the ions around that colloid to diffuse in and allow that colloid to grow rather than to form more colloids.

The Ag-Sb phase diagram includes a peritectic reaction which produces $\mathrm{Ag}_{3} \mathrm{Sb}$. This compound has the same atomic ratio as the doses sequentially implanted. Due to pressure considerations the temperature where the peritectic transformation occurs varies depending upon the colloid size. The $9 \mathrm{Ag} / 3 \mathrm{Sb}$ sample shown in Fig. 2 displays a shell like microstructure characteristic of a peritectic reaction. We attribute the development of this microstructure to the following: The large Ag particles, formed when $\mathrm{Ag}$ was implanted first as seen in the $9 \times$ $10^{16} \mathrm{Ag}$ sample, become nucleation sites for the $\mathrm{Sb}$ ions. Reaction interfaces develop at the surfaces of the $\mathrm{Ag}$ colloids. An annular shell of $\mathrm{Ag}_{3} \mathrm{Sb}$ is formed at these interfaces. As these shells grow thicker, the $\mathrm{Ag}$ and $\mathrm{Sb}$ atoms have to diffuse longer distances. Denuded zones develop around the large colloid producing a concentration gradient for diffusion. Because the diffusion of $\mathrm{Ag}$ is three orders of magnitude greater than that of $\mathrm{Sb}^{24,25}$ the Ag diffuses into the $\mathrm{Sb}$ and forms the islands around the larger particles as seen in Fig. 2. The d-spacings obtained from the diffraction ring patterns of this sample are indicative of elemental metallic $\mathrm{Ag}$ and a phase of $\mathrm{Ag}_{3} \mathrm{Sb}$, suggesting that the reaction has not reached single phase equilibrium and that the microstructure obtained displays an intermediate step of the reaction process.

The microstructure of the $3 \mathrm{Sb} / 9 \mathrm{Ag}$ sample is expected to develop similarly. However, initial implantation of $\mathrm{Sb}$ produces a high particle number density resulting in two important differences. First, more nucleation sites are available and second, a greater area of reaction interface would produce overlapping denuded zones. Because of these two factors the reaction is expected to proceed at a significantly enhanced rate. However, due to the slower diffusion of $\mathrm{Sb}$ there is a build-up of $\mathrm{Ag}$ ions in the matrix resulting in the formation of some $\mathrm{Ag}$ colloids. While most of the d-spacings obtained from the diffraction ring patterns of this sample are consistent with an $\mathrm{Ag}_{3} \mathrm{Sb}$ phase there are some which correspond solely to the dspacings of metallic Ag, suggesting that the reaction, though not at equilibrium, has created a sufficient amount of $\mathrm{Ag}_{3} \mathrm{Sb}$ to produce diffraction patterns.

The optical properties of these samples are a direct consequence of the microstructure observed. In principle the wavelength where the surface plasmon resonance occurs may be calculated from the equation, $\varepsilon_{1}+2 n_{\mathrm{d}}{ }^{2}=$ 0 , provided data for $\varepsilon_{1}$ is available. In the single element $\mathrm{Ag}$ implanted sample the absorption peak at $\sim 400 \mathrm{~nm}$ is attributed to the surface plasmon resonance of $\mathrm{Ag}$ particles $<20 \mathrm{~nm}$. The peak at $\sim 610 \mathrm{~nm}$ is attributed to the surface plasmon resonance of the largest $\mathrm{Ag}$ particles producing multipole resonances. ${ }^{26)}$ For the single element $\mathrm{Sb}$ implanted sample the lack of a resonance peak is attributed to the condition $\varepsilon_{1}+2 n_{\mathrm{d}}^{2}=0$ not being met.

The wavelength where the resonance peaks occur for the sequentially implanted samples is difficult to calculate from first principles due to varying composition of the colloids. Effective medium theory predicts that change in the dielectric function with changes in composition and coating of particles will result in a shifting of the resonance peak. ${ }^{20)}$ The shifting of this peak due to coating will depend strongly on the ratio of the material in the mantle to the material in the core. ${ }^{27}$

For the sequentially implanted $9 \mathrm{Ag} / 3 \mathrm{Sb}$ sample we attribute the broad peak at $\sim 335 \mathrm{~nm}$ to a surface plasmon resonance of partially coated $\mathrm{Ag}$ particles. Likewise, the broad peak at $\sim 534 \mathrm{~nm}$ is attributed to a quadrupole resonance of the largest partially coated $\mathrm{Ag}$ particles. The mantle of the $\mathrm{Ag}$ particles causing the shift of the resonance peak positions is $\mathrm{Ag}_{3} \mathrm{Sb}$. Since single element 
implanted $\mathrm{Sb}$ displays no resonance peaks, no resonance peaks due to $\mathrm{Sb}$ are expected in the sequentially implanted sample, though the particles symmetrically positioned around the large colloids are believed to be single element $\mathrm{Sb}$ colloids. The lack of sharp resonance peaks suggests that either the peritectic reaction, while producing enough $\mathrm{Ag}_{3} \mathrm{Sb}$ to partially coat the $\mathrm{Ag}$ colloids, has not produced enough of the metallic compound to display a resonance peak dependent upon $\varepsilon_{1}$ of $\mathrm{Ag}_{3} \mathrm{Sb}$, or that the resonance peak of the $\mathrm{Ag}_{3} \mathrm{Sb}$ is being masked by the resonance peak of the Ag. These results indicate that the $9 \mathrm{Ag} / 3 \mathrm{Sb}$ sequentially implanted sample is an intermediate step of the peritectic reaction.

The absorption spectrum for the sequentially implanted $3 \mathrm{Sb} / 9 \mathrm{Ag}$ sample displays two overlapping peaks positioned at $\sim 403 \mathrm{~nm}$ and $\sim 485 \mathrm{~nm}$. No higher order resonance peaks are expected in this sample due to the absence of large particles. We attribute the peak at $\sim 403$ $\mathrm{nm}$ to the surface plasmon resonance of the Ag particles produced from the build-up of $\mathrm{Ag}$ ions at the reaction interfaces, and the peak at $\sim 485 \mathrm{~nm}$ we attribute to the surface plasmon resonance peak of the metallic compound $\mathrm{Ag}_{3} \mathrm{Sb}$. This presence of two resonance peaks suggests that the peritectic reaction expected to take place for this composition, though not reaching equilibrium due to the presence of the $\mathrm{Ag}$ resonance peak, has produced enough metallic compound to display a resonance peak dependent upon $\varepsilon_{1}$ of $\mathrm{Ag}_{3} \mathrm{Sb}$.

\section{4. $2 \mathrm{Ag} / \mathrm{Cd}$ System}

$\mathrm{Ag}$ and $\mathrm{Cd}$ were implanted with a ratio of $6 \mathrm{Ag}$ to $6 \mathrm{Cd}$. This ratio was chosen because AgCd is a stable compound of the Ag-Cd system. Single element implanted samples were made using doses of $6 \times 10^{16} \mathrm{Cd}$ and $6 \times 10^{16} \mathrm{Ag}$. The sequentially implanted samples were made using these same doses of $\mathrm{Cd}$ and $\mathrm{Ag}$. One sample (6Ag/6Cd) was made implanting the $\mathrm{Ag}$ first then the $\mathrm{Cd}$ and a second sample $(6 \mathrm{Cd} / 6 \mathrm{Ag})$ by implanting the $\mathrm{Cd}$ first then $\mathrm{Ag}$.

Figure 4 shows the RBS spectra for the samples with $6 \mathrm{Ag}, 6 \mathrm{Cd}, 6 \mathrm{Ag} / 6 \mathrm{Cd}$ and $6 \mathrm{Cd} / 6 \mathrm{Ag}$. For the single element implantations the distributions as a function of depth from the surface are Gaussian in shape with the peaks at $\sim 0.14$ microns. The Cd implanted sample has a broader distribution of the implanted ions than the Ag implanted sample, while the Ag is more sharply peaked than the Cd. The FWHM is $\sim 0.1$ microns for the Cd implanted sample and $\sim 0.09$ microns for the Ag implanted sample. The RBS spectrum for the sequentially implanted $6 \mathrm{Cd} / 6 \mathrm{Ag}$ sample is a slightly skewed Gaussian with the peak at $\sim 0.15$ microns. Its FWHM is the same as for the Cd implanted sample. The dose as measured by RBS for the single element implantations is 5.0 and 4.8 for the $\mathrm{Cd}$ and Ag samples respectively. The total dose as mea-

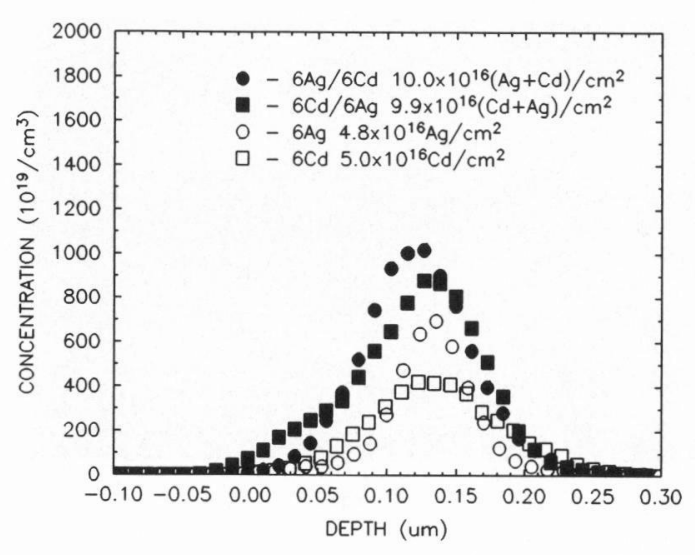

Fig. 4 Ion distributions as a function of depth from the surface for samples sequentially implanted with nominal doses of $6 \times 10^{16} \mathrm{Ag}$ ions $/ \mathrm{cm}^{2}$ and $6 \times 10^{16} \mathrm{Cd}$ ions $/ \mathrm{cm}^{2}$ and single element implants of $6 \times 10^{16} \mathrm{Ag}$ and $6 \times 10^{16} \mathrm{Cd}$. Numbers in parentheses are retained doses as measured by RBS.

sured by RBS for the Cd/Ag sample is $1.0 \times 10^{17}$ ions $/ \mathrm{cm}^{2}$ which agrees within error with that expected based on the single element implantations. We attribute differences between nominal doses and RBS measured doses to sputtering.

Micrographs of the $6 \mathrm{Ag}$ and $6 \mathrm{Cd}$ single element implanted samples reveal that the microstructure of the $\mathrm{Cd}$ sample displays approximately spherical colloids with no particles $>15 \mathrm{~nm}$ in diameter. Mean particle size for the Cd sample is $7.2 \pm 1.8 \mathrm{~nm}$ with a standard deviation of $2.2 \mathrm{~nm}$. Selected area diffraction patterns reveal that the colloids are polycrystalline $\mathrm{Cd}$. The microstructure of the Ag sample displays approximately spherical colloids with a broader particle size distribution than the single element $\mathrm{Cd}$ implanted sample. Mean particle size in the Ag sample is $13.5 \pm 1.8 \mathrm{~nm}$ with a significant number of particles larger than $25 \mathrm{~nm}$ and some as large as $40 \mathrm{~nm}$. The standard deviation in the $\mathrm{Ag}$ implanted sample is 8.8 nm. Selected area diffraction patterns reveal that the colloids are polycrystalline FCC Ag.

Bright field images obtained for the $6 \mathrm{Cd} / 6 \mathrm{Ag}$ and $6 \mathrm{Ag} / 6 \mathrm{Cd}$ samples are shown in Fig. 5. The microstructure of the sequentially implanted $6 \mathrm{Ag} / 6 \mathrm{Cd}$ sample displays a broad particle size distribution. This sample contains a high density of particles $<20 \mathrm{~nm}$ in diameter as well as particles reaching $40 \mathrm{~nm}$ in diameter. Mean particle size for the $6 \mathrm{Ag} / 6 \mathrm{Cd}$ sample is $8.5 \pm 1.8 \mathrm{~nm}$ with a standard deviation of $5.6 \mathrm{~nm}$. Electron diffraction patterns reveal that the particles are polycrystalline. The d-spacings obtained for the $\mathrm{Ag} / \mathrm{Cd}$ sample are most consistent with a phase of $\mathrm{Ag}-\mathrm{Cd}, \mathrm{AgCd}$, and elemental Cd. Due to measurement error unambiguous identification of the $\mathrm{Ag}-\mathrm{Cd}$ 


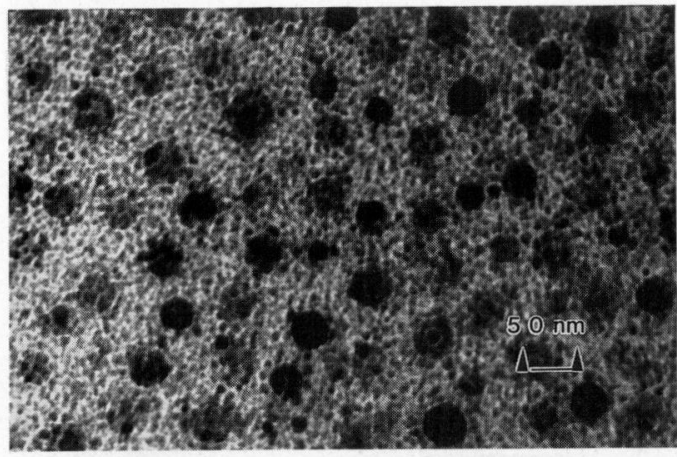

(a)

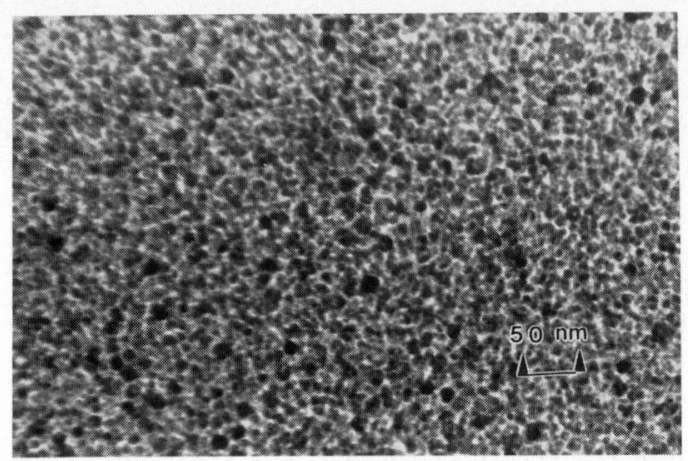

(b)

Fig. 5 Bright field images of the sequentially implanted $\mathrm{Ag}$ and Cd samples, (a) $6 \mathrm{Ag} / 6 \mathrm{Cd}$ and (b) $6 \mathrm{Cd} / 6 \mathrm{Ag}$.

phase was not possible.

The microstructure of the sequential $6 \mathrm{Cd} / 6 \mathrm{Ag}$ sample displays a high density of approximately spherical colloids with a narrower particle size distribution (no particles $>25 \mathrm{~nm}$ in diameter). Mean particle size for the $6 \mathrm{Cd} / 6 \mathrm{Ag}$ sample is $8.6 \pm 1.8 \mathrm{~nm}$ with a standard deviation of $3.0 \mathrm{~nm}$. Selected area diffraction patterns reveal that these colloids are polycrystalline. The d-spacings obtained from the ring pattern for the $\mathrm{Cd} / \mathrm{Ag}$ sample are most consistent with a phase of $\mathrm{Ag}-\mathrm{Cd}, \mathrm{Ag}_{5} \mathrm{Cd}_{8}$, and elemental Ag. Again due to measurement error unambiguous identification of the Ag-Cd phase was not possible.

Implanting $\mathrm{Ag}$ first followed by the implantation of $\mathrm{Cd}$ is similar to slowly adding $\mathrm{Cd}$ to $\mathrm{Ag}$ metal with the implantation process giving rise to radiation enhanced diffusion which serves as a driving force for the mixing of the ions. From the binary alloy phase diagram of $\mathrm{Ag}$ and $\mathrm{Cd}$ there are two equilibrium compounds with compositions $\mathrm{AgCd}$ and $\mathrm{Ag}_{5} \mathrm{Cd}_{8}$. Following the phase diagram of $\mathrm{Ag}-\mathrm{Cd}$, the first equilibrium compound reached is $\mathrm{AgCd}$. This is consistent with observations from electron diffraction measurements.

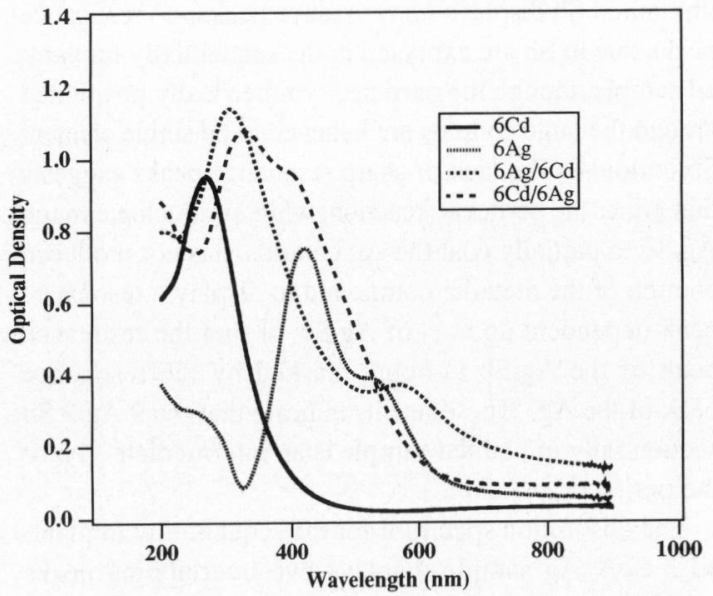

Fig. 6 Optical density as a function of wavelength for $6 \mathrm{Cd}$, $6 \mathrm{Ag}, 6 \mathrm{Ag} / 6 \mathrm{Cd}$ and $6 \mathrm{Cd} / 6 \mathrm{Ag}$ samples.

For the sample where $\mathrm{Cd}$ is implanted first, followed by the implantation of $\mathrm{Ag}$, the first equilibrium compound reached following the phase diagram of $\mathrm{Ag}-\mathrm{Cd}$ in this direction is $\mathrm{Ag}_{5} \mathrm{Cd}_{8}$. For the $6 \mathrm{Cd} / 6 \mathrm{Ag}$ sequentially implanted sample the electron diffraction pattern is that of an $\mathrm{Ag}-\mathrm{Cd}$ intermetallic phase, $\mathrm{Ag}_{5} \mathrm{Cd}_{8}$, and elemental Ag.

From TEM measurements the shape is similar for all implants so we do not expect any changes in the optical spectra based on particle shape differences. From electron diffraction measurements the single implantations of $\mathrm{Cd}$ and $\mathrm{Ag}$ result in the formation of randomly oriented polycrystalline metallic nanoclusters of $\mathrm{Cd}$ and $\mathrm{Ag}$ respectively.

Figure 6 shows the optical density as a function of wavelength for samples implanted with $6 \mathrm{Ag}, 6 \mathrm{Cd}$, $6 \mathrm{Cd} / 6 \mathrm{Ag}$, and $6 \mathrm{Ag} / 6 \mathrm{Cd}$. We attribute the peak at $403 \mathrm{~nm}$ in the Ag implanted sample to Ag colloids $<20 \mathrm{~nm}$ in diameter. The absorption shoulder at $530 \mathrm{~nm}$ we attribute to an additional higher order absorption term in Mie theory, i.e., the quadrupole term. ${ }^{20}$ The optical spectrum for the Cd implanted sample exhibits a peak at $271 \mathrm{~nm}$. We attribute this peak to the SPR of small metallic nanoclusters of Cd observed in the TEM micrographs. All nanoclusters were less than $20 \mathrm{~nm}$ in diameter and we expect only a dipole absorption term.

The absorption in the $6 \mathrm{Cd} / 6 \mathrm{Ag}$ as implanted sample is attributed to the superposition of two peaks. The position of these peaks was determined by a simple curve fit of a background absorption due to a $1 / \lambda$ dependence expected for nanometer dimension colloids and two Gaussian peaks. The best fit was obtained for peaks centered at 310 $\mathrm{nm}$ and $412 \mathrm{~nm}$. We attribute the peak at $310 \mathrm{~nm}$ to the 
formation of $\mathrm{Ag}_{5} \mathrm{Cd}_{8}$ and the peak at $412 \mathrm{~nm}$ to elemental $\mathrm{Ag}$. These assignments are consistent with electron diffraction results. ${ }^{28)}$

The absorption spectrum for the $6 \mathrm{Ag} / 6 \mathrm{Cd}$ sample seen in Fig. 6 is more complex. A curve fit to a superposition of three Gaussians centered at $271 \mathrm{~nm}, 323 \mathrm{~nm}$, and 573 $\mathrm{nm}$ with background absorption of $1 / \lambda$ gives the best fit to the observed $6 \mathrm{Ag} / 6 \mathrm{Cd}$ absorption spectrum. ${ }^{28}$ ) We attribute the peak centered at $323 \mathrm{~nm}$ to the formation of $\mathrm{AgCd}$, while the peak centered at $271 \mathrm{~nm}$ is attributed to the presence of elemental $\mathrm{Cd}$. The broad absorption peak centered at $573 \mathrm{~nm}$ is attributed to the larger particles, as observed in the TEM micrographs, contained in this sample producing a multipole resonance term. These assignments are consistent with electron diffraction results.

\section{4. $3 \mathrm{Ag} / \mathrm{Cu}$ System}

While the other two systems were chosen because a stable compound in either $\mathrm{Ag}-\mathrm{Cd}$ or $\mathrm{Ag}-\mathrm{Sb}$ existed, the $\mathrm{Ag}$ and $\mathrm{Cu}$ system was chosen because each element had been shown to form nanoclusters with distinct surface plasmon resonances. Sequentially implanted samples were implanted with varying ratios of $\mathrm{Ag}$ to $\mathrm{Cu}$. The ratios used were $3 \times 10^{16} \mathrm{Ag} / 9 \times 10^{16} \mathrm{Cu}(3 \mathrm{Ag} / 9 \mathrm{Cu})$, $6 \times 10^{16} \mathrm{Ag} / 6 \times 10^{16} \mathrm{Cu}(6 \mathrm{Ag} / 6 \mathrm{Cu})$, and $9 \times 10^{16} \mathrm{Ag} / 3$ $\times 10^{16} \mathrm{Cu}(9 \mathrm{Ag} / 3 \mathrm{Cu})$.

Backscattering measurements show that the $\mathrm{Cu}$ ions have a maximum concentration at $\sim 0.14$ microns beneath the surface, while the $\mathrm{Ag}$ ions show a maximum concentration at $\sim 0.13$ microns in the as implanted samples. ${ }^{17}$ In the sequentially implanted samples the total number of implanted ions is constant, within error, for all samples.

Figure 7 shows representative bright field (BF) images of the planar view of the implanted layer for the $3 \mathrm{Ag} / 9 \mathrm{Cu}$ and the $9 \mathrm{Ag} / 3 \mathrm{Cu}$ samples. The particles formed are uniform in shape and are spherical. Selected area diffraction patterns from the samples reveal that two distinct metallic crystal structures exist in the implanted layer and are the same for all three samples. Identical electron diffraction ring patterns for all ratios of implanted samples are indicative of pure $\mathrm{Ag}$ and pure $\mathrm{Cu}$ particles. This is in agreement with the $\mathrm{Ag}-\mathrm{Cu}$ phase diagram as no stable intermetallic compounds are predicted. However, ion enhanced diffusion caused by the implantation process, combined with overlapping ion distributions, would suggest that a reaction might occur between the $\mathrm{Ag}$ and $\mathrm{Cu}$ ions. Transmission electron micrographs of the single element Ag implanted samples demonstrate that $\mathrm{Ag}$ colloids are formed by implantation with particle sizes ranging from $5 \mathrm{~nm}$ to $45 \mathrm{~nm}$. Consequently, in the $\mathrm{Ag} / \mathrm{Cu}$ sequential implantations we assume that $\mathrm{Ag}$ colloids, which serve as nucleation sites for the $\mathrm{Cu}$ ions, have

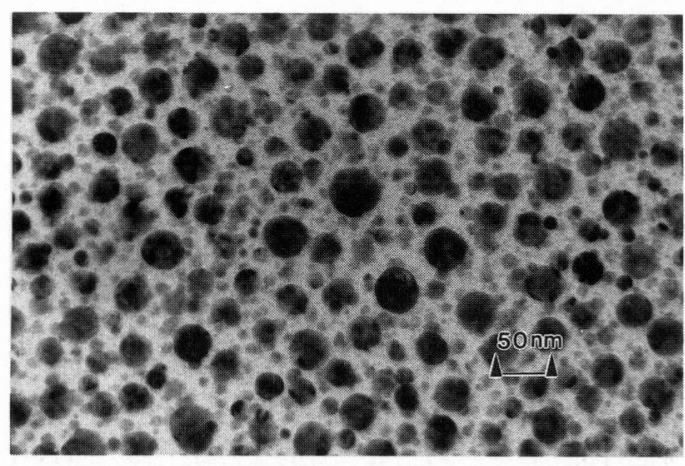

(a)

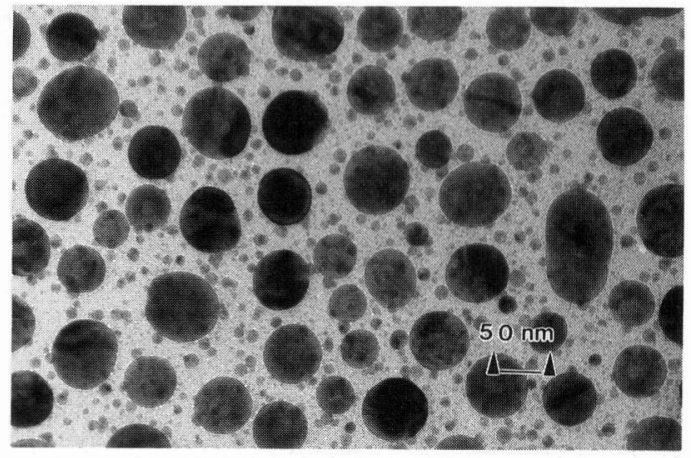

(b)

Fig. 7 Bright field images of the sequentially implanted $\mathrm{Ag}$ and Cu samples, (a) $3 \mathrm{Ag} / 9 \mathrm{Cu}$ and (b) $9 \mathrm{Ag} / 3 \mathrm{Cu}$.

been formed prior to the $\mathrm{Cu}$ implantation. From the $\mathrm{Ag}$ $\mathrm{Cu}$ phase diagram the maximum solubility of $\mathrm{Cu}$ in $\mathrm{Ag}$ is approximately 14 atomic $\%$. Once this limit has been exceeded the $\mathrm{Cu}$ precipitates out to form a pure $\mathrm{Cu}$ phase. The size distribution of $\mathrm{Ag}$ colloids formed in the sample suggests that the $\mathrm{Cu}$ precipitates out to form a coating on the smaller particles and does not exceed the solubility limit in the larger particles. This results in $\mathrm{Cu}$ coated $\mathrm{Ag}$ particles and pure $\mathrm{Ag}$ particles. This is consistent with what is observed from electron diffraction. The average particle size increases with increasing $\mathrm{Cu}$ dose. The mean size is $14.4,15.2$, and $17.5 \pm 1.8 \mathrm{~nm}$ for samples with $\mathrm{Ag} / \mathrm{Cu}$ ratios of $9 / 3,6 / 6$, and $3 / 9$, respectively.

Figure 8 shows the optical spectra for the $9 \mathrm{Ag} / 3 \mathrm{Cu}$, $6 \mathrm{Ag} / 6 \mathrm{Cu}$ and the $3 \mathrm{Ag} / 9 \mathrm{Cu}$ samples. Also shown for comparison are single element implantations of $9 \times$ $10^{16} \mathrm{Cu}$ ions $/ \mathrm{cm}^{2}$ and $3 \times 10^{16} \mathrm{Ag}$ ions $/ \mathrm{cm}^{2}$. The $9 \mathrm{Cu}$ sample shows an absorption peak at $\sim 575 \mathrm{~nm}$ and increasing absorption with decreasing wavelength. This peak is due to the surface plasmon resonance of small $(<20$ $\mathrm{nm}) \mathrm{Cu}$ nanoclusters. The absorption spectrum for the $3 \mathrm{Ag}$ sample is dominated by a sharp absorption peak at $\sim$ 


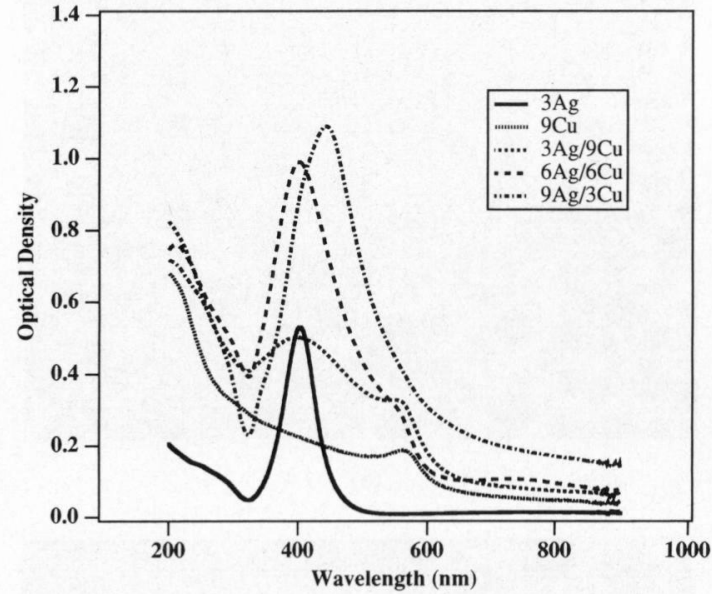

Fig. 8 Optical density as a function of wavelength for $3 \mathrm{Ag}$, $9 \mathrm{Cu}, 3 \mathrm{Ag} / 9 \mathrm{Cu}, 6 \mathrm{Ag} / 6 \mathrm{Cu}$ and $9 \mathrm{Ag} / 3 \mathrm{Cu}$ samples.

Table 2 Linear and nonlinear optical coefficients measured at $570 \mathrm{~nm}$.

\begin{tabular}{lccr}
\hline Sample & $\alpha\left(\mathrm{cm}^{-1}\right)$ & $n_{2}\left(\mathrm{~cm}^{2} / \mathrm{W}\right)$ & \multicolumn{1}{c}{$\beta(\mathrm{cm} / \mathrm{W})$} \\
\hline $9 \mathrm{Ag} / 3 \mathrm{Cu}$ & $5.9 \times 10^{4}$ & $1.0 \times 10^{-9}$ & $-3.8 \times 10^{-5}$ \\
$6 \mathrm{Ag} / 6 \mathrm{Cu}$ & $5.4 \times 10^{4}$ & $1.3 \times 10^{-9}$ & $-0.9 \times 10^{-5}$ \\
$3 \mathrm{Ag} / 9 \mathrm{Cu}$ & $4.6 \times 10^{4}$ & $1.6 \times 10^{-9}$ & $1.4 \times 10^{-5}$ \\
\hline
\end{tabular}

$403 \mathrm{~nm}$. This peak is attributed to small $(<20 \mathrm{~nm}) \mathrm{Ag}$ nanoclusters. The absorption in the $9 \mathrm{Ag} / 3 \mathrm{Cu}$ sample is dominated by a large broad peak at $\sim 440 \mathrm{~nm}$. TEM results show that this sample contains particles larger than $40 \mathrm{~nm}$, and we would expect two peaks from $\mathrm{Ag}$ due to both a dipole resonance and a quadrupole resonance. However this is not observed. In agreement with the results from electron diffraction measurements we conclude that the $\mathrm{Cu}$ ions essentially coat the $\mathrm{Ag}$, resulting in a shift of the resonance. ${ }^{21}$ With increasing $\mathrm{Cu}$ concentration the $440 \mathrm{~nm}$ peak shifts to lower wavelength and a shoulder at $570 \mathrm{~nm}$ appears. We interpret these results as indicating an increase in the thickness of the mantle of the $\mathrm{Cu}$ ions on the $\mathrm{Ag}$ clusters introduced with the first implant. In the $3 \mathrm{Ag} / 9 \mathrm{Cu}$ sample the $\mathrm{Cu}$ peak at $575 \mathrm{~nm}$ is observable and the $\mathrm{Ag}$ peak at $403 \mathrm{~nm}$ has become very broad. This is consistent with the $\mathrm{Cu}$ mantle becoming thicker.

Values calculated for the $n_{2}$ increase with increasing $\mathrm{Cu}$ dose and decreasing optical absorption are seen in Table 2. Enhancements of the nonlinear susceptibility of the composite are expected at or near the surface plasmon resonance of the metal colloids. ${ }^{1,13)}$

From Fig. 9 there is a clear change in the character of the two photon absorption coefficient, $\beta$, with changing

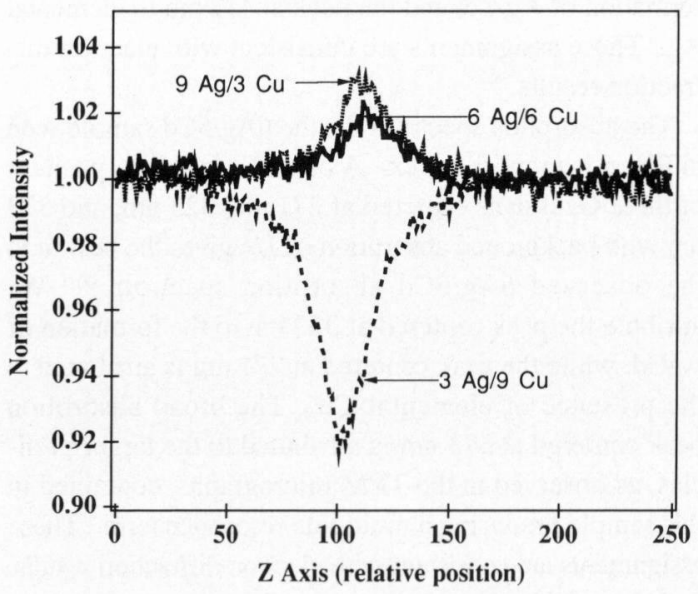

Fig. $9 \mathrm{Z}$-scan open aperture measurements for $3 \mathrm{Ag} / 9 \mathrm{Cu}$, $6 \mathrm{Ag} / 6 \mathrm{Cu}$ and $9 \mathrm{Ag} / 3 \mathrm{Cu}$ samples.

relative doses of $\mathrm{Ag}$ and $\mathrm{Cu}$. Table 2 gives the values calculated for $\beta$. With increasing $\mathrm{Ag}$ dose $\beta$ saturates. The role of the relative ratio of $\mathrm{Ag}$ to $\mathrm{Cu}$ in the two photon absorption processes is currently being studied.

The measurements of $n_{2}$ at $570 \mathrm{~nm}$ are closer to the surface plasmon resonance for $\mathrm{Cu}$ particles than they are to the surface plasmon resonance of $\mathrm{Ag}$ particles $(\sim 400$ $\mathrm{nm}$ ). These results indicate that the increase in $n_{2}$ is due to the presence of increasingly $\mathrm{Cu}$ rich particles with increasing $\mathrm{Cu}$ dose. However the presence of the $\mathrm{Ag}$ has a substantial impact on the nonlinear response of these composites. For a sample implanted with $\mathrm{Cu}$ to a dose of $6 \times 10^{16} \mathrm{ions} / \mathrm{cm}^{2}$ under similar conditions, we obtain a value of $3.4 \times 10^{-10} \mathrm{~cm}^{2} / \mathrm{W}$ for $n_{2}$. This is a factor of $\sim 5$ smaller than the sequentially implanted sample with the same $\mathrm{Cu}$ dose. While there is twice the nominal dose of metal ions present in the sequentially implanted sample, this factor of $\sim 5$ difference is too large to be accounted for by concentration differences alone, since $n_{2}$ should increase linearly with volume fraction, $p$, as shown in equation 2. Therefore the increase in $n_{2}$ is due to changes in the composition of the metal colloids with changing relative concentrations of $\mathrm{Ag}$ to $\mathrm{Cu}$. The presence of the $\mathrm{Ag}$ ions appears to enhance the nonlinear response of the $\mathrm{Cu}$ near its surface plasmon resonance frequency.

The values for $n_{2}$ increase by $\sim 60 \%$ while the absorptivity decreases by $\sim 25 \%$ with the change in relative concentrations of $\mathrm{Ag}$ to $\mathrm{Cu}$. We would expect the opposite behavior for a dominant thermal mechanism, i.e., the values for $n_{2}$ would increase with increasing absorptivity due to increased thermal loading of the sample. This observation of increasing $n_{2}$ with decreasing $\alpha$ indicates that the response has a strong electronic component 
and is not dominated by thermal mechanisms. As the electronic structure of the colloids, and hence the optical response, will be determined by the metal species, ${ }^{29}$ the observation that $n_{2}$ increases with $\mathrm{Cu}$ to $\mathrm{Ag}$ ratio indicates that the nonlinear response is related to the electronic structure of the colloids. This also indicates an electronic mechanism. Nonlinear measurements on $\mathrm{Cu}$ colloids formed by ion implantation have been reported previously. ${ }^{13)}$ Using similar wavelength, power, rep rate, and pulse width of the laser, the thermal loading of the sample was found not to dominate the response because of the relatively long interpulse spacing ( $263 \mathrm{~ns}$ ), even though the 6 ps pulse duration is comparable to the electron thermalization times of the $\mathrm{Cu}$ colloids. Based on the above discussion we conclude that the nonlinear response observed for these sequentially implanted samples is dominated by an electronic mechanism.

\section{Overview}

The addition of the second metal ion species changes both the microstructure and the optical response of the nanoclusters formed. In all three systems the microstructure and resulting optical properties are dependent upon which ion species are present. Sequential implantation is similar to slowly mixing in a second ion species to the metal colloids formed by the first ion species. Radiation enhanced diffusion and localized heating created by the implantation process serve as driving forces for the mixing of the ions. This process leads to three possible scenarios with respect to changes in the product microstructure. First is compound formation. The second is the coating of one nanocluster with the second metal, and third is the formation of distinct separate elemental nanoclusters. Combinations of these three are clearly possible as the implantation process may or may not proceed to equilibrium.

The formation of compounds depends on the existence of stable compounds of the two metal species, as in the case of the $\mathrm{Ag} / \mathrm{Sb}$ and $\mathrm{Ag} / \mathrm{Cd}$ systems. To a first approximation phase diagrams can be used to predict the product obtained. The amount of compound formation has been shown to depend on the order of implantation. In part this is due to the size and number of nanoclusters formed by the first implant. Decreasing the size of the nanoclusters and increasing the relative number of nanoclusters formed by the first metal species implanted gives rise to more surface area for the interaction of the second implanted species. This increase in surface area allows greater compound formation as observed in the case of the $3 \mathrm{Sb} / 9 \mathrm{Ag}$ sample compared to the 9 $\mathrm{Ag} / 3 \mathrm{Sb}$ sample.

Evidence for the coating of the first nanocluster by the second metal is observed in the case of the $\mathrm{Ag} / \mathrm{Cu}$ system. In the electron diffraction results $\mathrm{Ag}$ rich and $\mathrm{Cu}$ rich particles are observed, but no compound phases are observed. Coupled with the shifts in the surface plasmon resonance expected for coated particles, this supports the hypothesis that the $\mathrm{Ag}$ nanoclusters serve as nucleation sites for the $\mathrm{Cu}$ ions, allowing the $\mathrm{Cu}$ to form a mantle around the core of $\mathrm{Ag}$. With increasing $\mathrm{Cu}$, changes in the ratio of the core to mantle volume give rise to the differences observed in the optical spectra.

No system examined showed the dominance of the third possible scenario of separate single element nanoclusters. However in all the systems examined, the presence of elemental colloids along with various degrees of either compound formation or coating has been observed.

Comparison of the $9 \mathrm{Ag}, 9 \mathrm{Ag} / 3 \mathrm{Sb}$ and $9 \mathrm{Ag} / 3 \mathrm{Cu}$ samples demonstrates the broad range of changes that can occur when a second ion species is added. In one case there is compound formation while, in the second the initial nanocluster is coated. Extending the process by changing the order of implantation demonstrates that different compounds can be formed, as in the $\mathrm{Cd} / \mathrm{Ag}$ system. Analysis of these results suggests that there are several keys to predicting the possible products. First is the thermodynamics of the two metal ion species being implanted. Second is the ability of the first implanted species to form nanoclusters. The critical radius necessary for nanocluster formation is important for determining the size, and hence number, of particles formed for a given dose.

Effective medium theory predicts that the optical properties of the metal nanoclusters formed will depend on the dielectric function of the metal nanoclusters. Comparing absorption in Fig. 3 and Fig. 6 for the $3 \mathrm{Sb} / 9 \mathrm{Ag}$, $6 \mathrm{Cd} / 6 \mathrm{Ag}$, and $6 \mathrm{Ag} / 6 \mathrm{Cd}$ samples shows that compound formation leads to the presence of new surface plasmon resonances. These changes in the optical properties of the material are attributed to changes in the dielectric function of the metal nanoclusters and subsequently to changes in the optical properties of the composite as predicted by equations (1) and (3).

Effective medium theory for small non interacting particles in a dielectric predicts substantial enhancement of the nonlinear response of the composite for optical frequencies near the surface plasmon resonance (SPR) frequency. This enhancement is due to local field effects and results from dielectric confinement. A significant problem with metal colloid-glass composites for device applications is that both the linear and nonlinear absorption in general increase near the surface plasmon resonance frequency. This increase in absorption has deleterious 
effects on the relative figures of merit for devices operating near the SPR frequencies of these materials. ${ }^{30,31}$ Even away from the SPR frequencies, linear and nonlinear absorption can limit device possibilities. The ability to form unique metal colloid-glass composites with larger nonlinear responses while at the same time reducing absorption losses could significantly improve the feasibility of these materials for optical devices. The ability to form these "alloy" metal-glass composites by sequential ion implantation could significantly increase the value of such materials for optical applications by enhancing the nonlinear response and by changing the character of that response as observed in the $\mathrm{Ag} / \mathrm{Cu}$ system. The nonlinear results for the $\mathrm{Ag} / \mathrm{Cu}$ system suggest that the presence of the $\mathrm{Cu}$ mantle around the $\mathrm{Ag}$ core can increase the nonlinear response while simultaneously lowering the total absorption of the system.

\section{Ackmowledgememt}

The authors acknowledge the support of the Army Research Office under grant DAAH04-93-G-0123 and DAAH04-94-G-0147 and Oak Ridge National Laboratory, managed by Lockheed Martin Energy Research Corp. for the U.S. Department of Energy under contract number DE-AC05-96OR22464.

\section{References}

1) C. Flytzanis, F. Hache, M.C. Klein, D. Ricard and PH. Roussignol: "Progress in Optics". ed. by E. Wolf (North Holland, Amsterdam, 1991).

2) C.R. Bamford: "Colour Generation and Control in Glass, Glass Science and Technology”, vol. 2 (Elsevier, Amsterdam, 1977).

3) G.W. Arnold and J.A. Borders: J. Appl. Phys. 489, 1488 (1977).

4) G. Whichard, H. Hosono, R.A. Weeks, R.A. Zuhr and R.H. Magruder, III: J. Appl. Phy. 67, 7526 (1990).

5) Y. Takeda, T. Hioki, T. Mohohiro, S. Noda and T. Kurauchi: Nucl. Instrum. Methods B 91, 515 (1994).

6) Z. Pan, S.H. Morgan, D.O. Henderson, S. Park, R.A. Weeks, R.H. Magruder,III and R. A. Zuhr: Mat. Res. Soc. Symp. Proc. 316, 469 (1994).

7) R.H. Magruder, III, D. O. Henderson, S. H. Morgan and R. A. Zuhr: J. Non Cryst. Solids, 152, 258 (1993).

8) R.H. Magruder, III, R.A. Weeks, R.A. Zuhr and G. Whichard: J. Non-Cryst. Solids 129, 46 (1991).

9) D.E. Hole, P.D. Townsend, J.D. Barton, L. C. Nistor and J. Van Landuyt: J. Non-Cryst. Solids 180, 266 (1995).
10) L.C. Nistor: J. Van Landuyt: J.D. Barton, D.E. Hole, N.D. Skelland and P.D. Townsend: J. Non. Cryst. Solids 162, 217 (1993).

11) J. Stark, R.A. Weeks, D.L. Kinser and R.A. Zuhr: J. NonCryst. Solids 95/96, 685 (1987).

12) C.W. White, D.S. Zhou, J.D. Budai, R.A. Zuhr, R.H. Magruder, III and D.H. Osborne: Mat. Res. Soc. Proc. 316, 499 (1994).

13) R.H. Magruder, III, R.F. Haglund, L. Yang, J.E. Wittig and R.A. Zuhr: J. Appl. Phys. 76, 708 (1994).

14) A recent review is given by R. A. Weeks: "Materials Science and Technology", vol. 9, ed. by J. Zarzychi, (VCH, Weinheim, 1991).

15) P. Mazzoldi, G.W. Arnold, G. Bertoncello and F. Gonella: Nucl. Instrum. Methods B 91, 478 (1994).

16) R.A. Wood, P.D. Townsend, N.D. Skelland, D.E. Hole, J. Barton and C.N. Afonso: J. Appl. Phys. 74, 5754 (1993).

17) R.H. Magruder, III, J.E. Wittig and R.A. Zuhr: J. NonCryst. Solids 163, 162 (1993).

18) R.A. Zuhr, R.H. Magruder, III and J.E. Wittig: Mat. Res. Soc. Sym. Proc. 316, 457 (1994).

19) R.H. Magruder, III, T.S. Anderson, R.A. Zuhr and D. Thomas: Nucl. Instrum. Methods B 108, 305 (1996).

20) T.S. Anderson, R.H. Magruder, III, D.L. Kinser, R.A. Zuhr and D. Thomas: Nucl. Instrum. Methods B (1997), in press.

21) C.F. Bohren and D.R. Huffman: "Absorption and Scattering of Light by Small Particles”, (John Wiley and Sons, New York, 1983) .

22) M.J. Weber, D. Milam and W.L. Smith: Opt. Eng. 17, 463 (1978).

23) T.S. Anderson, R.H. Magruder, III, D.L. Kinser, R.A. Zuhr and D.K. Thomas: submitted to Journal of Materials Research.

24) Diffusion Information Center: Diffusion Data, 1, 5 (Cleveland, Ohio, 1967).

25) Diffusion Information Center: Diffusion Data, 2, 302 (Cleveland, Ohio, 1967).

26) T.S. Anderson, R.H. Magruder III, R.A. Zuhr and J.E. Wittig: J. Electron. Mater. 25, 27 (1996).

27) A.E. Neeves and M.H. Birnboim: J. Opt. Soc. Am. B 6, 787 (1989).

28) T.S. Anderson, R.H. Magruder, III, D.L. Kinser, R.A. Zuhr and D.K. Thomas: Nucl. Instrum. Mehods B, (1997), in press.

29) R.E. Hummel: "Electronic Properties of Materials", 2nd Ed. (Springer-Verlag, Berlin, 1993).

30) V. Mizrahi, K.W. DeLong, G.I. Stegeman, M.A. Salfi and M.J. Andrejcu: Opt. Lett. 14, 1140 (1989).

31) G.I. Stegeman and R.H. Stolen: J. Opt. Soc. Am. B 6, 652 (1989). 